\title{
Economy of Scale and Production of Rejects in the Production Planning Model
}

\author{
Khamiduulin Marat Raisovich \\ Isavnin Alexey Gennadevich
}

Branch of Kazan Federal University in Naberezhnye Chelny

Email: nayka_prom@mail.ru

\section{Doi:10.5901/mjss.2015.v6n2p267}

\begin{abstract}
The article presents an economic-mathematical model of production planning that takes into account the effect of economies of scale of production and release of defective products. Proposed new modified methods and algorithms for production planning model that takes into account the influence of several factors on profit maximization. Assessed the effectiveness of the results of applying mathematical apparatus for production planning model that takes into account the economies of scale of production and a certain percentage of defects of products.
\end{abstract}

Keywords: penalty function; total expenses; optimal strategy; given accuracy; support function; economies of scale of production.

\section{Introduction}

In many practically relevant situations, linear models describe the reality of economic processes adequately enough. However, there do exist such decision-making problems and operations, whose adequate description require use of nonlinear optimization models. Referred to such operations in which the mathematical model is of essentially non-linear nature are: the operations of manufacturing products in which it is necessary to consider economy of scale of production, as well as production of a certain percentage of rejects; the activities of a production firm in which the volume of the products manufactured is non-linearly dependent on expenditures of resources (model of the firm); the model «costs efficiency»; the problem of consumer choice, where the aim is to obtain maximum utility given consumer's limited budget (consumer's choice model), etc. It has to be pointed out as well that there do not exist any universal methods, which could be applied to any economic processes and phenomena. Therefore, there arises a need to develop new methods, which would enable more complex specific economic problems to be solved. The needs faced in the development of computing mathematics and information technologies, convex programming, optimization theory, economics have resulted in evolving accurate non-linear methods for search of an optimal solution. One can refer the following to such methods: graphical method, Newton's method, Lagrange multiplier method, penalty function method, etc. However, accurate methods do not always turn out to be the best and effective in the economic processes.

Therefore, development and practical importance of using alternative methods of solving non-linear models of economic processes (the model of production planning which considers production of rejects and production economy of scale) of the following form:

$$
f(x) \rightarrow \min \text {, }
$$

with the following limitations:

$f_{i}(x) \leq 0, \quad i \in I$,

is a topical task in the optimal running of a production operation. One of the methods to solve the convex programming problem is the penalty function method with incomplete minimization of auxiliary functions.

Analysis of optimal methods for certain separate economic processes shows that each method solves and describes a definite model of the economic system (production planning model, which considers rejects and production economy of scale). The majority of the models do not allow influence of several factors on products output to be considered (linear models). Therefore, such situation goes to show that there is a need for research into development of the methods of solving convex problems to manufacture products, in which it is required to take into consideration the production economy of scale as well as production of a certain percentage of rejects. An attempt at adequately modeling the products manufacture which considers production of rejects and production economy of scale, inevitably results in the optimization mathematical model being built (Zabotin 2004, p.46). 
Any production, along with output of quality products, is accompanied by production of defective or reject products or, to put it bluntly, scrap. Just as in the manufacture of good products, it also takes resources to produce scrap, however these resources are wasted away. Since volumes of resources are limited, these additional expenditures of resources on production of reject products result in large expenditures of resources and, as a consequence, lead to a reduction in the volume of good products. This, as a rule, causes the manufacturing cost of the products made to rise as well as revenues and profit generated by their sales to decrease (Madera 2010, p.419).

The second factor that exercises a material influence on the optimum production plan is the so called production economy of scale. The production economy of scale consists in the fact that with increased production volume, its manufacturing cost goes down, while revenue and profit generated by sales goes up. Economy of scale is predicated by a multitude of causes among which one can mention uniform rate of production, a stable sustainable level achieved by technology, repeatability of operations, innovations, full utilization of equipment, etc.

Modeling a production plan inclusive of rejects production and production economy of scale impacts various elements of the economic and mathematical model: both the objective function and the set of constraints. The main factor which accompanies output of rejects, is the increased expenditure of resources, therefore the modeling of rejects should, first of all, reflect on the constrains which express volumes of resources to be spent in production.

In its turn, economy of scale manifests itself in the reduced manufacturing cost of the products with increasing production volume and, respectively, in higher profit from their sales. As the total profit has been described by the objective function, the economy of scale is to affect precisely that.

Research objective is development of the methods and tools in planning model the production considering release of the rejected production and a scale effect of production promoting increase of efficiency of functioning of the enterprise as it is production - economic system. Achievement of the specified purpose demanded statement and the solution of the following research problems:

1. To develop economic - mathematical model of planning of production which considers release of the rejected production and a production scale effect.

2. To develop the new modified methods and algorithms for the planning model production considering influence of several factors (release of the rejected production and a production scale effect) on receiving the maximum profit.

3. To estimate efficiency of results of use of mathematical apparatus for production planning model which considers a scale effect of production and a certain percent of marriage of production.

4. To develop system of search of the optimum plan of production, which allows to get the maximum profit, thus considering a scale effect of production and some percent of marriage of production.

\section{Literature Review}

This section discusses the various definitions of a nonlinear optimization model of production based on economies of scale and production of defective products, the basics of the penalty function method with incomplete minimization of auxiliary functions.

\subsection{Definition of penalty function}

American mathematician Courant first used penalty method in 1943 (for the study of motion in a bounded domain). Method is widely used for solving the problems of local minimization in the 60s. One of the most popular program was SUMT (developers - Americans Fiakko and Mack McCormick). All methods of this group, despite the various schemes and options have one thing in common: they made the transition from a constrained optimization problem to an equivalent problem or sequence unconstrained optimization. The penalty function method can be divided into two classes: parametric and nonparametric.

Many domestic and foreign scientists were engaged in development of this scientific area: Kantorovich L.V., Pontryagin L.S., Lerner A.YA., Burkov V. N., A.A. Korbut, Krugman P., Mikhalevich V.S., Yu.I. Beet, A.A. Skrynnikov, Saffron milk caps YU.I., Anikin B. A., V.P. Korneenko, M. V. Sidelnikov, Johnson B., Bellman R., Hayek F., Hadley D., D. Tiksye, G. Pavellek, D. Stock, Wilson R., Howard R., and others.

About scale effects and connected production functions at different times outstanding foreign scientists economists K. Marx, Ch. Kobb, P. Douglas (production function of Kobba - Douglas) wrote, R. Solou.

Researches in the field of quality of production and decrease in marriage were carried out in works of Deminga U.E. (14 key principles), A. Feygenbauma (the theory of quality management). 
The analysis of optimum methods for separately taken economic processes shows that each method solves and describes a certain model of economic system (the production planning model considering release of the rejected production and a production scale effect). The majority of models don't allow to consider influence of several factors on production (linear models). Therefore such situation testifies to need of researches on development of methods for the solution of tasks of production in which it is necessary to consider a production scale effect, and also release of some percent of marriage. Attempt of adequate modeling of the production considering release of marriage and a scale effect of production inevitably leads to creation of nonlinear optimizing mathematical model.

\subsubsection{Parametric method}

Parametric methods are characterized by the presence of one or more appropriately selected parameters in the structure of the penalty function as weights.

Parametric methods include a method of sequential unconstrained optimization proposed Fiakko and McCormick (1961), method Zangwill et al (1969).

Parametric methods are divided into:

1) interior point methods;

2) methods of external point;

3) combined methods.

When using an interior point method current point is always within the permissible area using the penalty function, which in this case is called a barrier. Methods external point, on the contrary, generate a sequence of points that go beyond the permissible region, but within the given feasible solution. Finally, the combined method to be used in equality constraints in the optimization process some of the constraints are satisfied, and the other - no. However, achieving the desired solution all conditions within a predetermined tolerance executed.

\subsubsection{Nonparametric method}

In non-parametric methods, the objective function is considered as a function defining additional artificial restriction gradually uplotnyamoe as new information on the solution of the problem.

\section{Research Methodology}

Let us structure the economic and mathematical model of production optimal planning with maximization of income which takes into consideration the output of rejects and production economy of scale for the case where two types of products $A_{1}$ and $A_{2}$ are manufactured, to manufacture which three types of resources $S_{1}, S_{2}$ and $S_{3}$ are consumed. Let us introduce the following designations:

- $x_{1}$ and $x_{2}$, conventional units - production volumes of good products $A_{1}$ and $A_{2}$ (variable mathematical models) (conventional units may, for example, mean kilograms, tons, meters, pieces, etc.);

- $a_{i j}$ - expenditures of the $i$ - th resource $S_{i}(i=1,2,3)$, used to produce one conventional unit of the $j$ - th product $A_{j}(j=1,2)$;

- $b_{1}, b_{2}$ and $b_{3}$ conventional unit - volumes of resources available in stock;

- $c_{1}$ and $c_{2}$, monetary units / conventional units - expected profit form sale of one conventional unit of products $A_{1}$ and $A_{2}$.

To produce rejects, the same resources are used as to produce good products. Given that resources are limited and that some of the resources are used to produce rejects, the volumes of resources diminish for production of good products, which leads to reduction in the production volumes of good products. Therefore, total expenditure of resource $S_{i}(i=1,2,3)$ can be given as follows:

$\mathrm{V}=\mathrm{V}_{1}+\mathrm{V}_{2}$,

$\mathrm{V}$ - volume of consumed resource $S_{i}$;

$\mathrm{V}_{1}$ - volume of resource $S_{i}$, used to produce goods products;

$\mathrm{V}_{2}$ - volume of resource $S_{i}$, used to produce rejects.

Causes responsible for defects to develop are numerous and multifarious, they depend on production technology and are of accidental nature. To construct an economic and mathematical model which considers production of rejects, let us assume the following premise: volume of rejects increases with increase in product manufacturing volumes. Then 
the volume of resource $S_{i}(i=1,2,3)$, used to produce good products $A_{j}(j=1,2)$ in the volume of $x_{j}$, as well as rejects, is comprised of two parts, one of which in the volume of $a_{i j} x_{j}$ is used to produce only good products, while the other one, in the volume of $k_{i j} x_{j}^{2}$, is used to produce rejects. The coefficient $k_{i j}$ characterizes intensity of change in the consumption of resource $i$ when one conventional unit of rejects is produced for product $A_{j}$. Consequently, the cumulative revenue of resource $S_{i}$, used simultaneously to produce good products $A_{j}$, and to produce rejects, equals the following sum $a_{i j} x_{j}+k_{i j} x_{j}^{2}$.

As resource of the $S_{i}$ type is used to produce both product $A_{1}$, and to produce product $A_{2}$, the total volume of used resource $S_{i}$ is to amount to the following value $a_{i 1} x_{1}+k_{i 1} x_{1}^{2}+a_{i 2} x_{2+} k_{i 2} x_{2}^{2}$. Given that the volumes of resources $\mathrm{S}_{1}$, $\mathrm{S}_{2}$ and $\mathrm{S}_{3}$ used are constrained by variables $b_{1}, b_{2}$ and $b_{3}$ let us write down a system of constraints for the mathematical model, which, along with output of products, also considers output of rejects:

$$
\left\{\begin{array}{l}
a_{11} x_{1}+k_{11} x_{1}^{2}+a_{12} x_{2}+k_{12} x_{2}^{2} \leq b_{1}, \\
a_{21} x_{1}+k_{21} x_{1}^{2}+a_{22} x_{2}+k_{22} x_{2}^{2} \leq b_{2}, \\
a_{31} x_{1}+k_{31} x_{1}^{2}+a_{32} x_{2}+k_{32} x_{2}^{2} \leq b_{3} .
\end{array}\right.
$$

Thanks to the economy of scale, revenues from sale of one conventional unit of products go up with increase in the volume of products manufactured. Let us construct an economic and mathematical model which considers the factor of production scale.

The total profit from sale of one conventional unit of products of the $A_{j}(j=1,2)$ type is composed of two components. The first component equals $c_{j}$ and does not consider the effect of production scale (linear model), while the second one, i.e. the so called «added profit, conditioned by the effect of production scale» - equals $l_{j} x_{j}$, where the coefficient $l_{j}$ expresses intensity of change in the profit of one conventional unit of product $A_{j}$ with increase in its production volume. Since the total profit from sale of one conventional unit of product $A_{j}$, conditioned by the effect of production scale, equals $c j+l_{j} x_{j}$, the total profit from sale of all the good products $A_{j}$, manufactured in the volume of $x_{j}$, is to amount to $\left(j+l_{j} x_{j}\right) x_{j}$. Hence, the cumulative profit from sale of good products $A_{1}$ and $A_{2}$ (objective function), manufactured in the volumes of $x_{1}$ and $x_{2}$ is to amount to the following value $\left(c_{1}+l_{1} x_{1}\right) x_{1}+\left(c_{2}+l_{2} x_{2}\right) x_{2}$. Therefore, the objective function represents a non-linear function. Consequently, the economic and mathematical model, which considers the output of rejects and the effect of production scale, is given as follows:

$F=\left(c_{1}+l_{1} x_{1}\right) x_{1}+\left(c_{2}+l_{2} x_{2}\right) x_{2} \rightarrow \max$,

while a set of constraints is given as follows:

$$
\left\{\begin{array}{l}
a_{11} x_{1}+k_{11} x_{1}^{2}+a_{12} x_{2}+k_{12} x_{2}^{2} \leq b_{1}, \\
a_{21} x_{1}+k_{21} x_{1}^{2}+a_{22} x_{2}+k_{22} x_{2}^{2} \leq b_{2}, \\
a_{31} x_{1}+k_{31} x_{1}^{2}+a_{32} x_{2}+k_{32} x_{2}^{2} \leq b_{3} .
\end{array}\right.
$$

\subsection{Instrument}

This mathematical model (4), (5) is a non-linear optimization mathematical model which considers output of rejects and the effect of production scale. For such a model, it is necessary to use mathematical apparatus based on the method of penalty functions with incomplete minimization of auxiliary functions.

Problem (1) - (2) has been considered, where multitude $D=\left\{x \in R_{n}: f_{i}(x) \leq 0, i=\overline{1, m}\right\}$ has been determined. This problem is solved with defined accuracy $\varepsilon>0$ with reference to $f(x)$. The algorithms of the penalty method allowing detection of some point $x^{\prime} \in X^{*}$, where $X^{*}=x \in\left\{D(0): f(x)-f^{*} \leq \mathcal{E}\right\}$.

The work uses the penalty functions constructed for a certain multitude immersed into the allowable (Zabotin 2004, p.36). If we assume the following as such a multitude

$$
\begin{aligned}
& D(p)=\left\{x \in R_{n}: f_{i}(x)+p<0, i \in I\right\}, p>0 \text {, then the penalty function may have the following form: } \\
& V(x)=\sum_{i=1}^{m}\left(\max \left\{0, f_{i}(x)+p\right\}\right)^{2}, p>0
\end{aligned}
$$

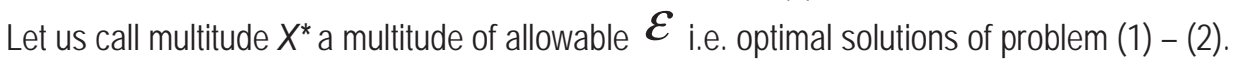

[1] has framed the definition $p$, i.e. approximability of the functions, which sums up the concept $p$, i.e. regularity of the constraints of the mathematical programming problems. It has been also proved that for any $\varepsilon>0$ there exists $p>0$, such that the inequality 
$\left|f(x(C))-f^{*}\right| \leq \varepsilon$

is valid with all $\mathrm{C}>0$, such that $x(C) \in D(0)$.

To value the $p$ parameter, the following supplementary conditions are required (Isavnin 2012).

Condition a) The $g(x)=\min \left\{f_{i}(x), i=\overline{1, m}\right\}$ function is uniformly convex on multitude $D(0)$ with non-decreasing module of convexity $\delta(t)$.

Condition b) There are numbers $p^{\prime} \in(0, \bar{p})$, where

$\bar{p} \in\left(0,-\inf \left\{g(x), x \in R_{n}\right\}\right)$, и $\bar{f}>\min f(x)$

$Q(t)=\left\{x \in R_{n}: f(x) \leq t\right\}$

are such that multitude $D\left(p^{\prime}\right) \cap Q(\bar{f})$ is constrained, where

Condition c) There exists number $\bar{p} \in(0,-\inf \{g(x), x \in R n\})$ such that the $f(x)$ objective function satisfies, on multitude $D(0) \cap Q\left(f_{\hat{p}}\right)$, Lipschitz condition with constant $L$, where $f_{\hat{p}}=\min _{x \in D(\hat{p})} f(x)$.

\section{Algorithm 5.}

Given required accuracy of solution $\varepsilon>0, x_{0} \in R_{n}$, natural number $N$, number $\delta \in(0 \mathcal{E})$. Choosing $0<p \leq \min \left(\frac{\beta \gamma \bar{\alpha}}{\left(V\left(x^{*}\right)-\gamma^{2} \bar{\alpha}\right) L}, p^{\prime}, \bar{p}\right)$, increasing function $\varphi(t)$ such that $\varphi(1) \geq 0, \varphi(N)=\frac{L p}{\beta s(1-s)^{s-1} \bar{\alpha}^{p}} ; k$ is set to 1 .

1. Computing $C_{k}=\varphi(k)$

2. If $k<N$, then finding an approximate solution of the problem $\min _{x \in R_{n}} F\left(x, C_{k}\right)$. Go to step 1 with $k$ set to $k+1$.

3. If $k=N$, then finding point $\mathrm{x}_{N} \in \mathrm{A}(\bar{\alpha})$,which is $\delta$-optimal by composed function solution of the problem $\min _{x \in R_{n}} F\left(x, C_{N}\right)$. Point $\mathrm{X}_{\mathrm{N}}$ is set to $\delta$ - the solution of problem (1) - (2) (Isavnin 2014, p.107).

\section{Algorithm 6.}

Given required accuracy of solution $\mathcal{E}>0, x_{0} \in R_{n}$, natural number $N$, number $\delta \in(0 \varepsilon)$. Choosing $0<p \leq \min \left(\frac{\beta \gamma(\varepsilon-\delta)}{\left(1-\gamma^{2}\right) L}, p^{\prime}, \bar{p}\right)$, increasing function $\varphi(t)$ such that $\varphi(1) \geq 0, \varphi(N)=\frac{L p}{\beta s(1-\gamma)^{s-1} \bar{\alpha}^{p}} \cdot k$ is set to 1. Choosing penalty function $V(x)=\max \{g(x)+p, 0\}^{s}, s \geq 1$.

1. Computing $C_{k}=\varphi(k)$

2. If $k<N$, then finding an approximate solution of the problem $\min _{x \in R_{n}} F\left(x, C_{k}\right)$. Go to step 1 with $k$ set to $k+1$.

3. If $k=N$, then finding point $x_{N} \in A(\bar{\alpha})$,which is $\delta$-optimal by composed function solution of the problem $\min _{x \in R_{n}} F\left(x, C_{N}\right)$. Point $x_{N}$ is set to $\delta$ - the solution of problem (1) - (2) (Isavnin 2014, p.108).

$p$ is set to $p(\varepsilon), p>0$ such that from including $x(C) \in D(0)$ will result the inequation $\left|f(x(C))-f^{*}\right| \leq \varepsilon$

$L$ - Lipschitz constant for the functions $f(x)$, evaluated for range $G, L>0,|f(x)-f(y)|<L\|x-y\|, \forall x, y \in G$ and $G \subset R_{n}$;

$\beta, \gamma$ - approximation parameters, where $\gamma \in[0,1), \beta>0$;

$\delta-^{-1}(p)$ - function that is reciprocal to module of convexity $\delta(p)$ and $0<p<\hat{p}$;

$C_{k}$ - penalty coefficient computed according to the following rule: $C_{k}=a^{*} k$, where $a-$ parameter that is used for computing of the penalty coefficient;

range $A(\bar{\alpha})$ - approximation of allowable set;

$g(x)$ - uniformly convex function for range $D(0)$ with non-decreasing module of convexity $\delta(p)$;

convex and closed set $D(0)$ satisfies Slater condition, that is $\{x: x \in R, g(x)<0\}=\varnothing$;

point $x^{*} \in \operatorname{Argmin} \quad\{f(x), x \in D(0)\}$;

$\hat{p}$-number, where $\hat{p} \in\left(0,-\inf \left\{g(x), x \in R_{n}\right\}\right.$;

$p^{\prime}$ - number, where $p^{\prime} \in(0, \bar{p})$, where $\bar{p} \in\left(0,-\inf \left\{g(x), x \in R_{n}\right\}\right)$;

$V(x)$ - penalty function;

$k$ - iteration index;

$\bar{\alpha}$ - number, where $\bar{\alpha}=\max \{\bar{\alpha}: A(\bar{\alpha}) \subset D(0)\}$ 


\subsection{Participants}

KAMAZ OJSC and the German concern ZF have recently opened a new building of ZF KAMA, their joint venture company, to produce transmissions. KAMAZ Leasing Company is a subsidiary of KAMAZ OJSC and offers to buy products on leasing basis. ZF Kama produces two types of transmissions Ecosplit-16s151 and Ecosplit - 16s1820 and in the process it uses 369 types of parts for transmission assembly. Manufacture of the products, apart from good products, is also accompanied by production of a certain quantity of rejects. Thanks to German technologies and innovations, the producer ZF Kama succeeded in achieving the effect of production scale, as a result of which with increasing volumes of products made, their manufacturing cost goes down and the profit rises.

Table 1.1 lists numerical values of resources expenditure to produce one conventional unit (pc.) of good products (coefficient $\mathrm{a}_{\mathrm{ij}}$ ) and resources expenditures to produce one conventional unit ( $\mathrm{pc}$.) of rejects (coefficients $\mathrm{k}_{\mathrm{ij}}$ ).

Profit values (mn. Rbls) as generated by sale of one conventional unit (pc.) of products without including (coefficients $\mathrm{c}_{\mathrm{j}}$ ) and including (coefficients $\mathrm{l}_{\mathrm{j}}$ ) the effect of production scale are set out in Table (1.2).

It is required to find an optimal plan for products manufacture, i.e. production volumes $x_{1}$ and $x_{2}$ of good products, i.e. Ecosplit -16s151 and Ecosplit - 16 s1820 transmissions, which is to ensure that maximum cumulative profit is made.

Table 1.1. Expenditure of Resources To Produce One Conventional Unit (pc.) of Ecosplit-16s151 and Ecosplit - 16s1820 Products

\begin{tabular}{|c|c|c|c|c|c|c|}
\hline \multirow[t]{3}{*}{ Resources (Spare Parts) } & \multirow{3}{*}{ No. } & \multicolumn{4}{|c|}{$\begin{array}{c}\text { Expenditure of Resources To Produce One Conventional Unit } \\
\text { (Pc.) of Good }\left(\mathbf{a}_{\mathbf{i j}}\right) \text { and Reject }\left(\mathbf{k}_{\mathrm{ij}}\right) \text { Products Ecosplit-16s151 } \\
\text { and Ecosplit - 16s1820, Conventional Unit (Pc.) }\end{array}$} & \multirow{3}{*}{$\begin{array}{l}\text { Constraints on } \\
\text { Resources (Spare Parts) } \\
\left(\mathbf{b}_{\mathrm{i}}\right), \text { Conventional Unit }\end{array}$} \\
\hline & & \multicolumn{2}{|c|}{ Ecosplit-16s151 } & \multicolumn{2}{|c|}{ Ecosplit - 16s1820 } & \\
\hline & & $a_{i 1}$ & $k_{i 1}$ & $a_{i 2}$ & $\boldsymbol{k}_{i 2}$ & \\
\hline $\begin{array}{l}\text { PNEUMATIC AND } \\
\text { HYDRAULIC BOOSTER } \\
\text { FOR CLUTCH } \\
\text { DISCONNECT }\end{array}$ & 1 & 2.9 & 0.0026 & 8.7 & 0.0073 & 4582 \\
\hline BOLT 10x110 & 2 & 3.2 & 0.0032 & 9.1 & 0.0023 & 4769 \\
\hline BOLT 10x140 & 3 & 2.5 & 0.0056 & 8.8 & 0.0045 & 4436 \\
\hline BOLT 10x28 & 4 & 4.1 & 0.0039 & 3.2 & 0.0022 & 4563 \\
\hline BOLT 10x35 Z1 & 5 & 3.4 & 0.0027 & 2.7 & 0.0065 & 3345 \\
\hline BOLT 10x40 & 6 & 2.6 & 0.0044 & 4.8 & 0.0032 & 3896 \\
\hline BOLT10X50 & 7 & 3,1 & 0,0022 & 3,5 & 0,0014 & 3980 \\
\hline f.................. & $\ldots$ & $\ldots \ldots \ldots$ & $\ldots \ldots \ldots \ldots$ & $\ldots \ldots \ldots$ & $\ldots \ldots \ldots \ldots \ldots$ & $\ldots \ldots \ldots \ldots \ldots$ \\
\hline 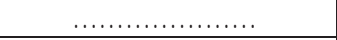 & $\ldots$ & $\ldots \ldots \ldots$ & $\ldots \ldots \ldots \ldots$ & $\ldots \ldots \ldots$ & $\ldots \ldots \ldots \ldots \ldots$ & $\ldots \ldots \ldots \ldots \ldots \ldots$ \\
\hline SPLITTER ENABLE ROD & 363 & 4.2 & 0.0022 & 3.1 & 0.0039 & 4368 \\
\hline $\begin{array}{c}\text { DE-MULTIPLIER ENABLE } \\
\text { ROD }\end{array}$ & 364 & 8.5 & 0.0065 & 3.3 & 0.0027 & 3097 \\
\hline $\begin{array}{c}\text { REVERSE ENABLE ROD } \\
\text { AND FORK } \\
\end{array}$ & 365 & 7.3 & 0.0032 & 2.7 & 0.0044 & 3543 \\
\hline $\begin{array}{l}\text { FIRST AND SECOND } \\
\text { GEAR ENABLE ROD AND } \\
\text { FORK }\end{array}$ & 366 & 6.2 & 0.0014 & 2.3 & 0.0022 & 4125 \\
\hline $\begin{array}{l}\text { THIRD AND FOURTH } \\
\text { GEAR ENABLE ROD AND } \\
\text { FORK }\end{array}$ & 367 & 3.4 & 0.0067 & 3.6 & 0.0074 & 4279 \\
\hline GEAR SHIFT ROD & 368 & 2.7 & 0.0035 & 2.3 & 0.0087 & 3492 \\
\hline CLUTCH M10x1 & 369 & 2.3 & 0.0022 & 4.2 & 0.0024 & 3987 \\
\hline
\end{tabular}


Table 1.2. Profit from Sale of One Conventional Unit of Ecosplit-16s151 and Ecosplit-16s1820 Products

\begin{tabular}{|c|c|c|c|}
\hline \multicolumn{4}{|c|}{$\begin{array}{l}\text { Profit from Sale of One Conventional Unit (Pc.) of Ecosplit-16s151 and Ecosplit-16s1820 Products, which considers }\left(l_{j}\right) \\
\text { and does not consider }\left(c_{j}\right) \text { the effect of product scale, mn. Rbls. }\end{array}$} \\
\hline \multicolumn{2}{|c|}{$\begin{array}{r}\text { Ecosplit-16s151 } \\
\end{array}$} & \multicolumn{2}{|c|}{ Ecosplit-16s1820 } \\
\hline$c_{1}$ & $l_{1}$ & $c_{2}$ & $l_{2}$ \\
\hline 140 & 0.09 & 433 & 0.017 \\
\hline
\end{tabular}

The mathematical model which considers output of rejects and the effect of production scale is given by (4), (5). Substituting the pre-determined values of the parameters, we shall arrive at the following:

$\mathrm{F}=140 \mathrm{x}_{1}+0,09 \mathrm{x}_{1}^{2}+433 \mathrm{x}_{2}+0,017 \mathrm{x}_{2}^{2} \rightarrow \max$,

and a system of 369 constraints:

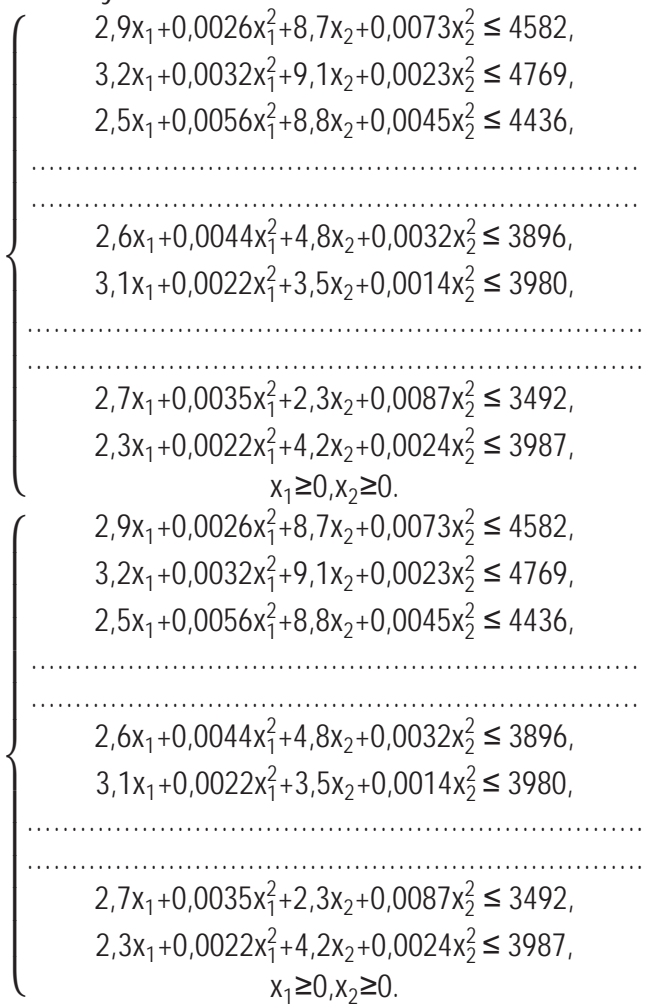

Let us reduce the problem to the following form (1) - (2):

$F=-140 x_{1}-0,09 x_{1}^{2}-433 x_{2}-0,017 x_{2}^{2} \rightarrow \min$, with the system of constraints:

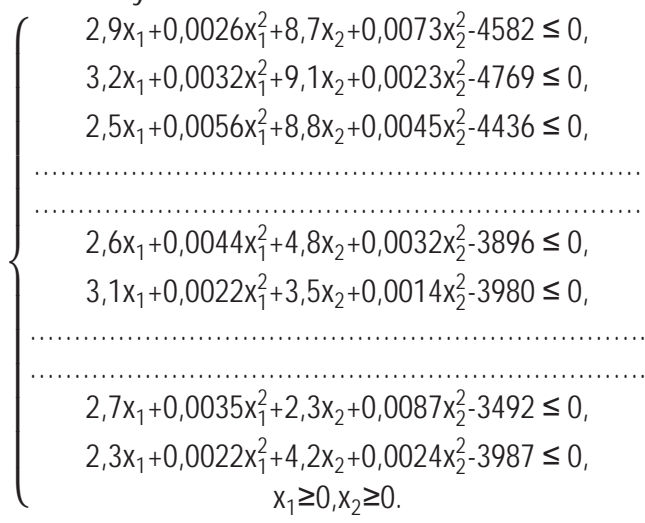




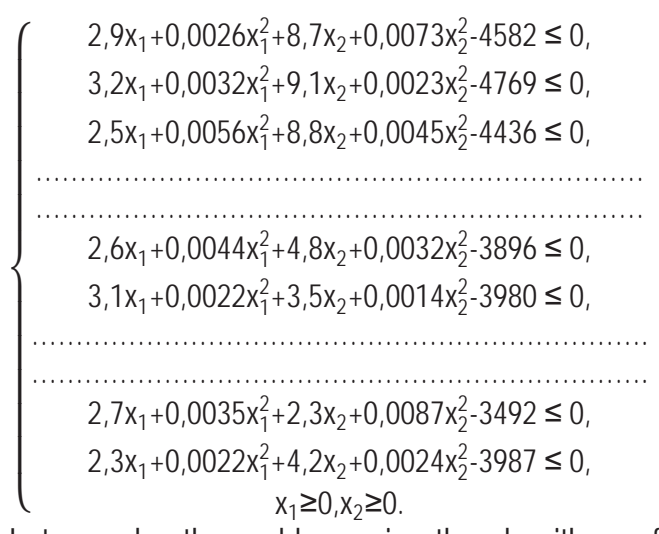

Let us solve the problem using the algorithms of the penalty function method with incomplete minimization of the auxiliary function (Isavnin 2012, p.130):

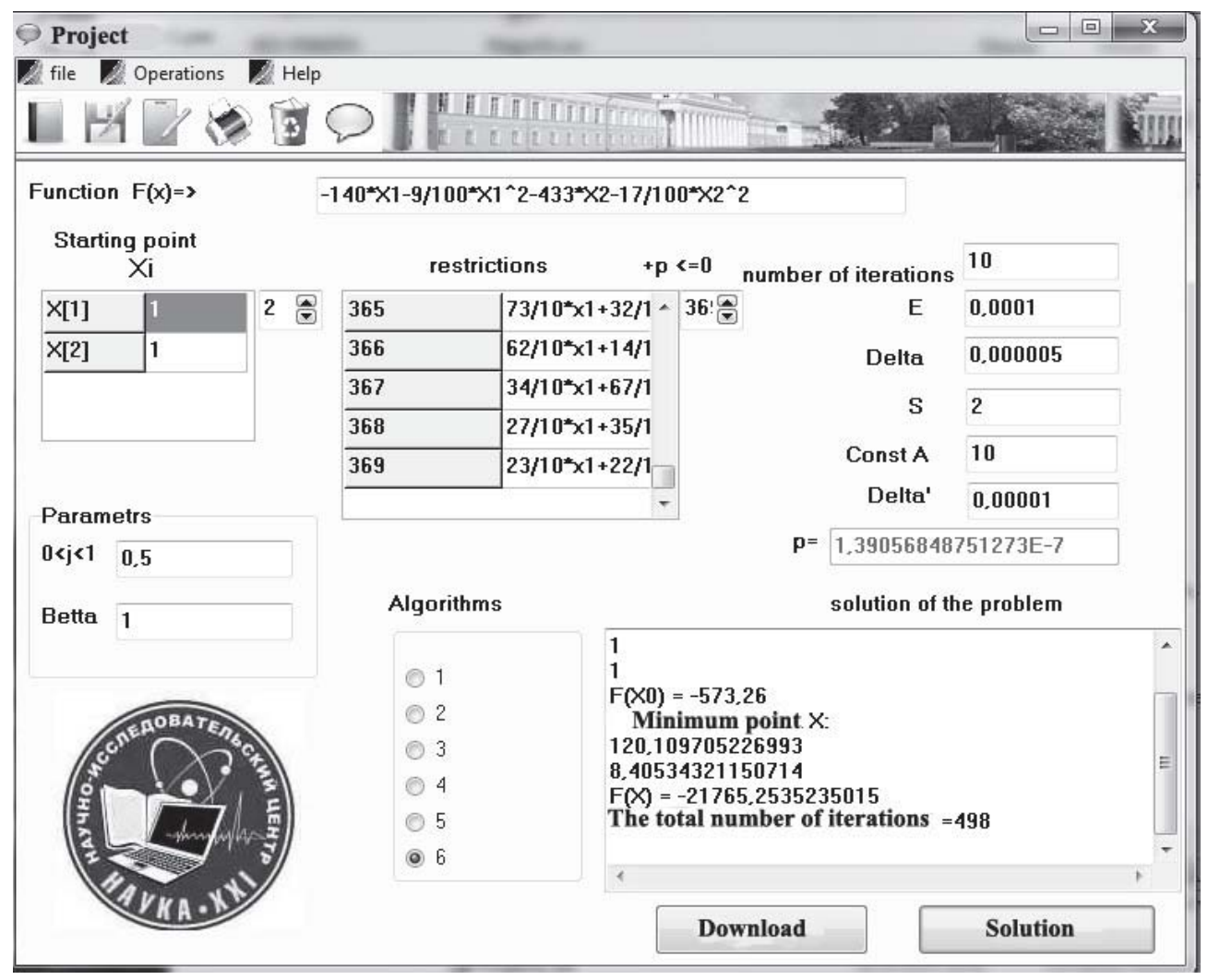

Fig 1. Solving the Problem of Production Planning With Consideration Given To Output of Rejects and the Effect of Production Scale

The results of numerical solution of this non-linear mathematical model have the following form: $x_{1}=120.1, x_{2}=8.4$, Fmax $=21.7 \mathrm{mn}$. rbls.

The optimum values of the model variables obtained and the maximum value of the objective function mean that for the maximum value of cumulative profit to be achieved ( $F \max =21.7 \mathrm{mn}$. Rbls.) with existence of rejects output and the effect of production scale, it would be required to produce 120 (units) Ecosplit-16s151 transmissions and 8 (units) Ecosplit-16s1820 transmissions.

In order to assess the influence of rejects output and the economy of scale, let us compare the optimal plans and maximum profit for three productions scenarios (Table 1.3):

1. Output of rejects and economy of scale are lacking. The operation is modeled using 
the linear model.

2. Production is accompanied by rejects and economy of scale. The operation is modeled using the non-linear model

3. Production is accompanied by output of rejects, but economy of scale is lacking.

Table 1.3. Comparison of Optimal Plans for the Three Production Scenarios

\begin{tabular}{|l|c|c|c|}
\hline \multirow{2}{*}{ Production Scenarios } & \multicolumn{3}{|c|}{$\begin{array}{c}\text { Optimal Production Volumes } \boldsymbol{x}_{\mathbf{1}}, \boldsymbol{x}_{2} \text { (Conventional Units) of Ecosplit-16s151 and } \\
\text { Ecosplit-16s1820 Products and Maximum Cumulative Profit } \boldsymbol{F}_{\max } \text { (mn. Rbls) }\end{array}$} \\
\cline { 2 - 4 } & $\boldsymbol{x}_{\mathbf{1}}$ & $\boldsymbol{x}_{\mathbf{2}}$ & $\boldsymbol{F}_{\max }$ \\
\hline 1. Rejects and Economy of Scale are lacking & 153 & 12 & 33,2 \\
\hline $\begin{array}{l}\text { 2. Accompanied by Output of Rejects and } \\
\text { the Effect of Production Scale }\end{array}$ & 120 & 8 & 21,7 \\
\hline $\begin{array}{l}\text { 3. Accompanied by Output of Rejects and } \\
\text { the Economy of Scale is lacking }\end{array}$ & 136 & 17 & 17,6 \\
\hline
\end{tabular}

Existence of rejects when products are manufactured significantly reduces the cumulative production volume which is caused by limitations on the resources available to the producer. Economy of scale (with existence of rejects) causes maximum profit to increase and exercises significant influence on the optimal plans for manufacture of products. Neglect of the influence exercised by the production factors, i.e. existence of rejects and production economy of scale, results in inadequate values of the optimal products output, which considerably differ from the real ones.

\section{Concluding Remarks}

The most important results that have defined the scientific novelty and significance of the study include the following:

1. An economic and mathematical model using algorithms penalty function method with incomplete minimization of auxiliary functions to generate the optimal plan of production and sales, taking into account the issue of defective products and economies of scale of production, thus optimizing the level of required reserves, plan production and sales in order to maximize profits.

2. Developed and proposed a modified algorithm penalty function method with incomplete minimization of auxiliary functions for optimal production planning model that takes into account the release of defective products and the effect of scale that reduce the complexity of computation and increase the speed of problem solving in 4 times in comparison with the method of penalty functions 2.5 times in comparison with the method of penalty functions using vneshnekvadratichnogo fine.

3. On the basis of algorithms for the penalty function method with incomplete minimization of auxiliary functions developed a system to support decision making and finding the optimal plan of production and sales with limited resources, taking into account the influence of several factors of production (production of defective products and economies of scale of production) in order to obtain maximum income and profits. Created application allows you to calculate the maximum profit, taking into account the economies of scale of production and the release of a certain number of defective products.

4. The approbation of the developed models and tools at JSC "Leasing Company KAMAZ". The results obtained allowed to determine the effect of economies of scale and issue marriage to choose the optimal production plan.

5. The presence of defective products at release significantly reduces the total volume of production of quality products.

6. Economies of scale leads to an increase in the maximum profit and has a significant impact on the optimal product roadmaps.

7. Neglecting the effect of marriage as a fact issue and economies of scale of production leads to inadequate values of optimum output, significantly different from the real ones.

Prospects for further development of the theme is to explore the use of algorithms in other areas, the development of improved and simple methods for solving economic problems and problems of convex programming, change multiplicative parameters to compare the efficiency with other methods and models. 


\section{References}

Isavnin, A.G., and Khamidullin, M.R. (2014). Determining of total expenses for the objective of equipment replacement. Life science journal, 11(6), 107-108.

Isavnin, A.G., and Khamidullin, M.R. (2012). About algorithms for the penalty function method with

incomplete minimization of auxiliary functions. Recent scientific developments. Retrieved on January 20, 2012 from the following World Web Site: http://www.ukrnauka.ru/ANR/20-01-2012_A4_tom-19.pdf

Isavnin, A.G., and Khamidullin, M.R. (2012). Software package for solving the problem of the optimal inventory control algorithms penalty method. Bulletin IzhSTU, 3(55), 130-132.

Madera, A.G.(2010). Modeling and decision-making in the management .Moscow: LKI.

Zabotin, Ya.I., Fukin I.A..(2004). Algorithms in the penalty method with approximation of the admissible set. 